\title{
Smooth regional estimation of low-flow indices: physiographical space based interpolation and top-kriging
}

\author{
S. Castiglioni ${ }^{1}$, A. Castellarin ${ }^{1}$, A. Montanari ${ }^{1}$, J. O. Skøien ${ }^{2,5}$, G. Laaha ${ }^{3}$, and G. Blöschl ${ }^{4}$ \\ ${ }^{1}$ School of Civil Engineering (Dept. DICAM), University of Bologna, Italy \\ ${ }^{2}$ Department of Physical Geography, University of Utrecht, The Netherlands \\ ${ }^{3}$ Institute of Applied Statistics and Computing, University of Natural Resources and Life Sciences, BOKU Vienna, Austria \\ ${ }^{4}$ Institute for Hydraulic and Water Resources Engineering, Vienna University of Technology, Vienna, Austria \\ ${ }^{5}$ Institute for Environment and Sustainability, Joint Research Centre, European Commission, Italy
}

Received: 10 September 2010 - Published in Hydrol. Earth Syst. Sci. Discuss.: 23 September 2010

Revised: 22 February 2011 - Accepted: 28 February 2011 - Published: 4 March 2011

\begin{abstract}
Recent studies highlight that spatial interpolation techniques of point data can be effectively applied to the problem of regionalization of hydrometric information. This study compares two innovative interpolation techniques for the prediction of low-flows in ungauged basins. The first one, named Physiographical-Space Based Interpolation (PSBI), performs the spatial interpolation of the desired streamflow index (e.g., annual streamflow, low-flow index, flood quantile, etc.) in the space of catchment descriptors. The second technique, named Topological kriging or Top-kriging, predicts the variable of interest along river networks taking both the area and nested nature of catchments into account. PSBI and Top-kriging are applied for the regionalization of $Q_{355}$ (i.e., a low-flow index that indicates the streamflow that is equalled or exceeded 355 days in a year, on average) over a broad geographical region in central Italy, which contains 51 gauged catchments. The two techniques are cross-validated through a leave-one-out procedure at all available gauges and applied to a subregion to produce a continuous estimation of $Q_{355}$ along the river network extracted from a $90 \mathrm{~m}$ elevation model. The results of the study show that Top-kriging and PSBI present complementary features. Top-kriging outperforms PSBI at larger river branches while PSBI outperforms Top-kriging for headwater catchments. Overall, they have comparable performances (Nash-Sutcliffe efficiencies in cross-validation of 0.89 and 0.83 , respectively). Both techniques provide plausible and accurate predictions of $Q_{355}$ in ungauged basins and represent promising opportunities for regionalization of low-flows.
\end{abstract}

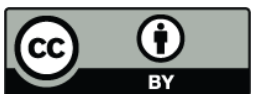

Correspondence to: A. Castellarin (attilio.castellarin@unibo.it)

\section{Introduction}

Hydrological predictions generally have to deal with the inadequacy or deficiency of observations for the site of interest (see the decade on Prediction in Ungauged Basins promoted by the International Association of Hydrological Sciences IAHS; Sivapalan et al., 2003). The prediction of low-flows indices in ungauged basins is a fundamental yet critical task in a number of engineering applications related to surface water resources planning and management. For instance, the assessment of surface water availability in ungauged basins is essential for studying the water quality of rivers and water bodies, or for evaluating project feasibility and for designing micro hydroelectric plants, which are gaining a lot of attention lately from the public and private sectors (Penche, 1998).

The regionalization of the low-flow regime is a central topic in this research area (see e.g., Smakthin, 2001; Castellarin et al., 2004; Laaha and Blöschl, 2006a; Castiglioni et al., 2009), as it can be conveniently applied to surface water assessment in ungauged basins. The scientific literature reports a number of regionalization studies in which the availability of surface water and other hydrological attributes can be evaluated at a given ungauged site on the basis of the data collected at basins that are hydrologically similar to the site of interest (see e.g., Vogel and Kroll, 1992; Ludwig and Tasker, 1993; Furey et al., 2000; Brath et al., 2002; Brath et al., 2003).

Recent studies show that techniques, which have been originally adopted for the spatial interpolation of point data (see e.g. kriging interpolators, De Marsily, 1986; De Marsily and Ahmed, 1987), can be effectively applied for regionalization of hydrometric information (Skøien et al., 2006; Skøien and Blöschl, 2007; Chokmani and Ouarda, 2004). In

Published by Copernicus Publications on behalf of the European Geosciences Union. 
particular, two different approaches to apply spatial interpolation for prediction of the streamflow regime in ungauged basins have been reported in literature. A first approach, named Topological kriging or Top-kriging, uses a description of the morphology and nested structure of the study area for spatially interpolating the streamflow index of interest (e.g., flood quantiles, low-flow indices, etc.) along the stream network (Skøien et al., 2006; Skøien and Blöschl, 2007).

A second approach spatially interpolates the hydrometric index of interest in a two-dimensional space of physiographical and climatic descriptors, the so-called physiographical space (Chokmani and Ouarda, 2004). The x and y coordinates of the physiographical space are derived from an adequate set of $n>1$ geomorphoclimatic catchment descriptors through the application of multivariate techniques such as the Principal Component Analysis (PCA) or Canonical Correlation Analysis (Chokmani and Ouarda, 2004; Hundecha et al., 2008). In particular, with the Physiographical-Space Based Interpolation, or PSBI, any given basin (gauged or ungauged) can be represented as a point in the $\mathrm{x}-\mathrm{y}$ space described above; in the same way the set of gauged basins of the study area can be represented by a cloud of points in this space. The empirical values of the quantity of interest (e.g., flood quantile, low-flow index, long-term annual streamflow, etc.) can be represented along the third dimension $z$ for each gauged catchment, and can then be spatially interpolated by applying a standard interpolation algorithm. The spatial interpolation enables one to represent the quantity of interest over the entire portion of the $\mathrm{x}-\mathrm{y}$ space containing empirical data, and therefore to estimate it at ungauged sites lying within the same portion of the space.

The literature reports successful applications of PSBI to the problem of regionalization of flood frequency regime (Chokmani and Ouarda, 2004) or low-flows (Castiglioni et al., 2009). The scientific literature also reports a successful application of PSBI in the context of regionalization of rainfall-runoff parameters (Hundecha et al., 2008), a topical issue in hydrology (see e.g., Bardossy, 2007; Yadav et al., 2007; Castiglioni et al., 2010) to which Top-kriging is also applicable.

Although rather different in their approach to regionalization, Top-kriging is intimately connected to the stream network structure and geometric layout (i.e., Top-kriging is only dependent on catchment boundaries), while PSBI relies on the identification of an orthogonal space to represent hydrological proximity. These methodologies share a common background idea: both perform a smooth regionalization of streamflow indices seamlessly over the stream network (Topkriging) or the physiographical space (PSBI) without defining or identifying homogeneous regions or pooling-groups of sites (see e.g., Burn, 1990; Reed et al., 1999; Castellarin et al., 2001). The approaches avoid the phase of catchment grouping, or catchment classification, a challenging task which is generally performed through procedures that are associated with some elements of subjectivity, and whose practical usefulness for predictions in ungauged basins is still an open and highly debated hydrological problem (see e.g., McDonnell and Woods, 2004). Furthermore, catchment grouping is often performed on the basis of streamflow indices (see e.g. Wagener et al., 2007), hence techniques that enable smooth regional estimation of streamflow indices may also be used to support and enhance catchment classification.

We present in this study a comparison of Top-kriging and PSBI aimed at assessing their ability in predicting low-flow indices in ungauged sites. We applied Top-kriging and PSBI to a geographical region in central Italy. The region includes 51 unregulated basins (i.e. absence of water withdrawals, or streamflow control structures, etc.), for which a number of geomorphoclimatic catchment descriptors are available (see also Castiglioni et al., 2009). The study focused on the prediction of $Q_{355}$, the daily streamflow that, on average, is equalled or exceeded 355 days in a year. Empirical values of $Q_{355}$ can be retrieved from annual flow-duration curves or duration curves constructed on the basis of the entire streamflow record (i.e. period-of-record flow-duration curves, Vogel and Fennessey, 1994). We refer to the latter case herein, since our interest is on long-term low-flow indices. $Q_{355}$ is commonly used in Italy as a low-flow index, and Castiglioni et al. (2009) showed for the study area that this low-flow index is highly correlated to two other commonly adopted lowflow indices, the daily discharge equalled or exceeded $95 \%$ of the time, $Q(95)$, and the 7-day discharge with a recurrence interval of 10 years, 7Q10 (also see e.g., Smakhtin, 2001; Laaha and Blöschl, 2006b; Gustard et al., 1992; Telis, 1992).

The comparison is performed at two different spatial scales: (1) regional scale; (2) catchment scale.

1. We assess the ability of each technique to predict $Q_{355}$ through a comprehensive leave-one-out cross validation procedure for the entire study region.

2. We then apply both methodologies to a large catchment of the study area to better analyse and interpret their accuracy and reliability for predicting $Q_{355}$ along the stream network.

The analysis enables us to assess the performances of Topkriging and PSBI and to compare advantages and disadvantages associated with the application of each methodology, gaining additional insights on the applicability and usefulness of the two spatial interpolation techniques for the prediction of streamflow indices in the context of the Prediction in Ungauged Basins (PUB) initiative.

\section{Smooth regional estimation through spatial interpolation}

Spatial interpolation is herein used to regionalize low-flows, by applying universal kriging over a two-dimensional space of catchment descriptors (PSBI) and Top-kriging over a geographical space. In general, kernel smoothing techniques can 
be applied to interpolate spatially autocorrelated variables, where the spatial coordinates may either identify geographical location (this is the case for the so-called geostatistical techniques) or a position in a generic bidimensional space. In particular kriging is a method for optimizing the estimation of a quantity that is distributed in space and measured at a network of points (see e.g., Journel and Huijbregts, 1978; De Marsily, 1984; Isaaks and Srivastava, 1989; Rossi et al., 1992; Chokmani and Ouarda, 2004). In kriging, the spatial interpolation is obtained by a linear combination of the observed values according to the following equation:

$\hat{Z}\left(x_{0}\right)=\sum_{i=1}^{N} \lambda_{i} Z\left(x_{i}\right)$

where $\hat{Z}\left(x_{0}\right)$ is the prediction of the variable of interest, $Z$, at location $x_{o}, Z\left(x_{i}\right)$ is the observed value at point (basin) $x_{i}$, with $i=1,2 \ldots N$, and $\lambda_{i}$ is a weighting coefficient. These weights are estimated by considering spatial correlation and configuration of the observations through variogram models fitted to experimental variograms. An experimental variogram expresses the semivariance between observations as a function of distance and direction of pairs of sampling locations, and describes the spatial correlation structure of the sample data (see e.g., Journel and Huijbregts, 1978; Cressie, 1993).

In practical applications, theoretical variogram models are fitted to experimental variograms to ensure a positive-definite covariance matrix. The literature proposes several theoretical variograms (linear, spherical, gaussian, exponential variogram, etc., see for instance Cressie, 1993; Journel and Huijbregts, 1978).

\subsection{PSBI: Physiographical Space-Based Interpolation}

The physiographical space-based interpolation applies spatial interpolation techniques, such as kriging, to the physiographical space defined by the catchment descriptors of the selected group of basins. PSBI is a kernel smoothing technique that uses a covariance based kernel. It should not be termed a geostatistical technique as it does not explicitly address autocorrelation of observations or residuals in geographic space in strict sense (see Pebesma, 2010). The space is defined using two orthogonal coordinates $\mathrm{x}$ and $\mathrm{y}$, which can be computed as a function of geomorphoclimatic catchment descriptors; so basins with similar characteristics have similar coordinates in physiographical space. Recently, several studies have applied interpolation techniques on physiographical space defined through different methodologies (Chokmani and Ouarda, 2004). One of them is Principal Component Analysis technique (PCA).

PCA is an exploratory multivariate statistical method which is often used to reduce the dimensionality of complex datasets. PCA allows to transform a $n$-dimensional space into a new space defined by $m$ variables (namely principal

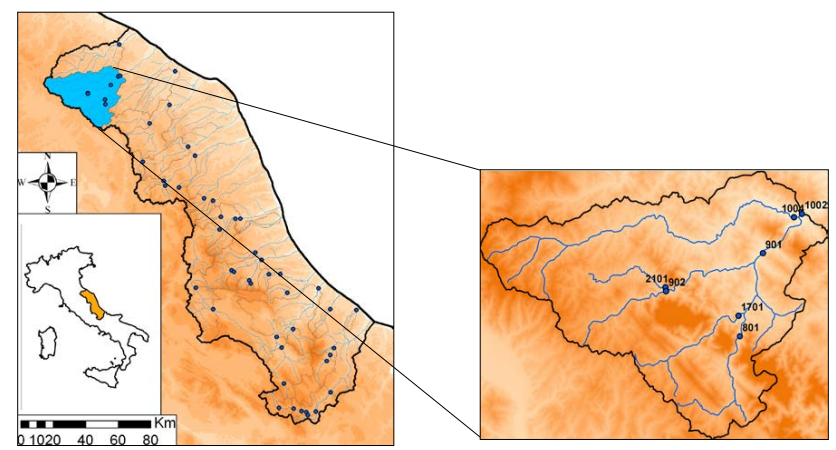

Fig. 1. Study area: 51 hydrometric stations (left); Metauro catchment (right).

components), with $m$ between 1 and $n$, which are linear combinations of the original variables. The principal components are uncorrelated and orthogonal to one another. They are ordered in such a way that the first component explains the largest amount of variance in the original dataset; the second explains the largest remaining amount of variance, and so on. When reducing the dimensionality of a given dataset, the selection of the appropriate number of principal components can be based upon one of the criteria reported in the literature (i.e. explained variance, Kaiser criterion, scree diagram test; Jackson, 1991; Cattell, 1966). Therefore PCA enables one to present most of the variability present in the original dataset in the first $m$ principal components. In particular, the first and second principal components, which are uncorrelated and orthogonal, can be used to define a two-dimensional space for applications of spatial interpolation techniques (Chokmani and Ouarda, 2004; Castiglioni et al., 2009).

\subsection{Top-kriging}

In Top-kriging (Skøien et al., 2006; Skøien and Blöschl, 2007), catchment runoff is conceptualised as a spatially continuous process which exists at any point in the landscape, and stream flow is the integral of local runoff over the catchment. The main idea of Top-kriging is to combine two groups of forcings for hydrological variability. The first group consists of variables that are continuous in space such as rainfall, evapotranspiration and soil characteristics, which are related to local runoff generation. In Top-kriging, the variability of these continuous processes in space is represented by the variogram. The second group of forcings is related to runoff aggregation and routing along the stream network. In Topkriging the aggregation effects are represented by the catchment boundaries associated with each point on the stream network. Rather than using variograms directly, Top-kriging uses point variograms averaged over the catchment areas. These averaged variograms depend on the point variogram as well as the sizes and the relative positions of the two catchments that are compared by the variogram. 
Table 1. Geomorphological and climatic descriptors of the 51 study catchments: drainage area, $A$; main channel length, $L$; percentage of permeable area, $P$; maximum, mean and minimum elevations, $H_{\mathrm{max}}, H_{\text {mean }}$ and $H_{\min } ; \Delta \mathrm{H}=\mathrm{H}_{\text {mean }}-H_{\text {min }}$; concentration time, $\tau_{\mathrm{c}}$; MAP; specific $Q_{355}, q_{355}$.

\begin{tabular}{lrrrrrrrrrr}
\hline & $\begin{array}{r}A \\
\left(\mathrm{Km}^{2}\right)\end{array}$ & $\begin{array}{r}P \\
(\%)\end{array}$ & $\begin{array}{r}H_{\max } \\
(\mathrm{m})\end{array}$ & $\begin{array}{r}H_{\text {mean }} \\
(\mathrm{m})\end{array}$ & $\begin{array}{r}H_{\min } \\
(\mathrm{m})\end{array}$ & $\begin{array}{r}\Delta \mathrm{H} \\
(\mathrm{m})\end{array}$ & $\begin{array}{r}L \\
(\mathrm{Km})\end{array}$ & $\begin{array}{r}\tau_{\mathrm{c}} \\
(\mathrm{h})\end{array}$ & $\begin{array}{r}\text { MAP } \\
\left(\mathrm{mm} \mathrm{year}^{-1}\right)\end{array}$ & $\begin{array}{r}q_{355} \\
\left(1 \mathrm{~s} \mathrm{~s}^{-1} \mathrm{Km}^{-2}\right)\end{array}$ \\
\hline Max & 3082.0 & 99.0 & 2914 & 1950 & 1103 & 1543 & 159.9 & 18.9 & 1530 & 45.92 \\
Mean & 355.7 & 49.1 & 2091 & 974 & 371 & 603 & 36.2 & 6.4 & 1104 & 5.13 \\
Min & 14.4 & 0.1 & 280 & 178 & 3 & 158 & 5.3 & 0.9 & 820 & 0.03 \\
75th perc. & 450.4 & 79.0 & 2570 & 1196 & 471 & 852 & 50.3 & 8.9 & 1221 & 6.47 \\
50th perc. & 168.4 & 46.0 & 2208 & 1035 & 269 & 525 & 26.0 & 4.9 & 1115 & 3.16 \\
25th perc. & 96.8 & 20.5 & 1596 & 632 & 174 & 387 & 18.0 & 3.7 & 980 & 1.63 \\
\hline
\end{tabular}

The application of Top-kriging involves two steps. In the first step, a point variogram model needs to be estimated from the data. This is done by estimating a sample variogram from the data, not only based on the centre-tocentre distance between catchments, but also on their size. From this, the point variogram model can be back-calculated by fitting aggregated variogram values to the sample variogram. In a second step, the point variogram is aggregated to the sizes and positions of the catchments for which the hydrometric index of interest is to be estimated and kriging is performed to predict the variables at the ungauged locations (Skøien et al., 2006; Skøien and Blöschl, 2007; Skøien et al., 2009; http://www.math.uni-klu.ac.at/stat/Tagungen/ statgis/2009/StatGIS2009_Skoien_1.pdf). Top-kriging provides both the estimates as well as the kriging variance (uncertainty).

\section{Study area and available data}

The study area includes 51 gauged basins $(\sim 2.8$ gauges per $1000 \mathrm{~km}^{2}$ ) for which daily streamflows are available for different observation periods with a minimum record length of 5 years (see Fig. 1 and Castiglioni et al., 2009). Daily streamflow series refer to the time-span 1921-2000 and were collected, validated and published by the Italian National Hydrographic Service (SIMN, Servizio Idrografico e Mareografico Nazionale).

For each river basin, a number of physiographical and climatic descriptors are available, namely: drainage area, $A$ $\left(\mathrm{km}^{2}\right)$; main channel length, $L(\mathrm{~km})$; percentage of permeable area, $P(\%)$; maximum, mean and minimum elevations, $H_{\text {max }}, H_{\text {mean }}$ and $H_{\text {min }}$ (ma.s.1.); average elevation relative to $H_{\text {min }}, \Delta \mathrm{H}=\mathrm{H}_{\text {mean }}-H_{\text {min }}(\mathrm{m})$; concentration time, $\tau_{\mathrm{c}}$ (hours) estimated according to Giandotti's (1934) empirical formula, and mean annual precipitation, MAP ( $\mathrm{mm} \mathrm{year}^{-1}$ ), (see e.g., Castellarin et al., 2004; Castiglioni et al., 2009). These characteristics are summarised in Table 1 in terms of maximum, mean and minimum values and 25th, 50th and 75th percentiles. Table 1 also describes the variability of the empirical values of specific $Q_{355}, q_{355}$. These values show that the study area presents some degrees of heterogeneity from a hydrological point of view, the major sources of variability being the sizes of the considered basins, their permeability and altimetric characteristics, and mean annual precipitation; an analysis of air temperature regimes at catchment scale (i.e., mean annual and monthly temperatures) revealed a limited variability (see also Castellarin et al., 2004 and Castiglioni et al., 2009). Also, Table 1 shows that empirical $q_{355}$ values are larger than zero for all study catchments. It is worth remarking here that the prediction of low-flow indices in ephemeral catchments is an important topic (e.g., Croker et al., 2003). Concerning the applicability of PSBI and Top-kriging, in principle, both techniques can be used for regions with ephemeral catchments. Nevertheless, given that both techniques predict the streamflow indices through a weighted average of empirical values, the application of the approaches in ungauged basins may be biased for catchments characterized by extremely high (underestimation may tend to prevail) or extremely low (overestimation may tend to prevail) values of the index. In this context though, the term "extremely" has to be intended relative to the majority of available empirical data. Concerning PSBI, predictions of $Q_{355}$ may not necessarily be positively biased if a signi?cant portion of the physiographic space contains primarily catchments for which the empirical values of the low-flow index are equal to zero. The same holds for Top-kriging, positive bias may be limited if large portions of the study stream network are characterized by zero flows.Concerning the catchment scale application, our study focuses on the Metauro catchment (see Fig. 1). The Metauro's basin morphology is analyzed on the basis of the SRTM $90 \mathrm{~m}$ Digital Elevation Model, DEM (see Consortium for Spatial Information, CGIAR-CSI, www.cgiar-csi.org), which was produced by NASA during the NASA Shuttle Radar Topographic Mission (SRTM). The soil properties of Metauro's basin are retrieved from a pedo-lithological map of Marche and Abruzzo (see e.g., Centamore et al., 1991; Vezzani and Ghisetti, 1998). 


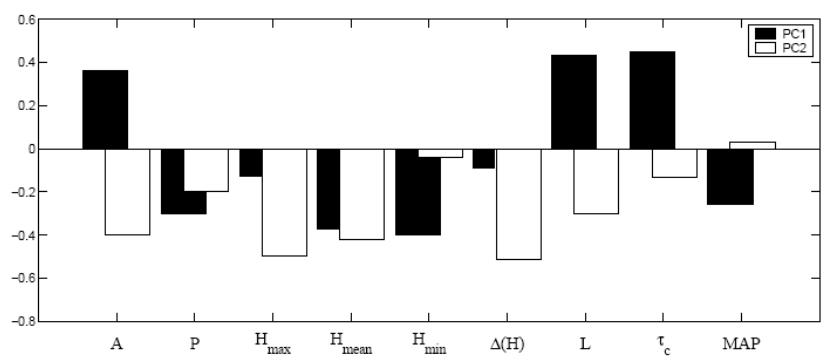

Fig. 2. Coefficients of each geomorphoclimatic descriptor for calculating the first two principal components by linear combination.

\section{Structure of the analysis and results}

As already mentioned, our analysis focuses on $Q_{355}$ and compares the prediction ability of PSBI and Top-kriging. To gain a more comprehensive understanding of the potential of the two techniques, the analysis applies them at regional and catchment scales. Both methodologies predict $Q_{355}$ in ungauged sites by applying a spatial interpolation of the streamflow index. The main difference between the methodologies lies on the support used for performing the interpolation. PSBI performs the spatial interpolation in the space of catchment descriptors, whereas Top-kriging predicts the variable of interest directly along the river network. As it will be shown, this fundamental difference is central to the interpretation of the different and complementary performances of PSBI and Top-kriging.

\subsection{Regional-scale analysis}

\subsubsection{PSBI}

PSBI was applied by using universal kriging. This spatial interpolator was selected on the basis of previous analysis performed over the same geographical area, which showed the superior performance of universal kriging interpolator relative to deterministic interpolators (i.e., inverse distance weighted, IDW, and Thiessen polygons) for the application of PSBI to the prediction of $Q_{355}$ in ungauged basins (see Castiglioni et al., 2009). Castiglioni et al. (2009) also showed that kriging-based PSBI outperforms in crossvalidation standard regional multiregression models.

Universal kriging was performed over the physiographical space defined by two orthogonal coordinates. The coordinates were identified from the set of nine geomorphoclimatic descriptors illustrated in Table 1 by performing a Principal Components Analysis (PCA, Basilevsky, 1994; Chokmani and Ouarda, 2004; Castiglioni et al., 2009). We resorted to PCA to reduce the dimensionality of catchment descriptors because our study focuses on the prediction of one hydrometric variable only, namely $Q_{355}$, and therefore we could not utilise Canonical Correlation Analysis (CCA, see e.g., Chockmani and Ouarda, 2004). Principal Components were not scaled, they were computed for normalized catchment descriptors by referring to the correlation matrix. The linear combination coefficients for the first two principal components are depicted in Fig. 2. The first two principal components present eigenvalues greater than one, which is required by the Kaiser criterion, and explain together about $70 \%$ of the variability of the original set of physiographical and climatic descriptors.

Several theoretical variogram models reported by the literature (i.e., exponential, Gaussian, Bessel, circular, spherical, pentaspherical for the anisotropic and isotropic cases) were tested and cross-validated in a series of preliminary analyses and the best predictions of the quantity of interest were obtained with an isotropic spherical model. The three parameters of the variogram model were fitted through a Weigthed Least Squares (WLS) method of the routine fit.variogram of the R-package gstat (Pebesma, 2004). Figure 3 reports empirical and theoretical variograms for the study region.

\subsubsection{Top-kriging}

Regional application of Top-kriging for the entire study area utilises as input data watershed boundaries for the 51 considered basins. These boundaries have been previously identified on the basis of a set of 1:100.000 topographic maps. This information is used in Top-kriging for reproducing the nested structure of the catchments, and for carrying out the discretization of study basins into square cells, and for calculating distances between cells of the grid for the discretized catchments (Skøien et al., 2006).

A modified exponential variogram is adopted as theoretical model (see e.g., Skøien, 2009); the model is fitted to the empirical variogram (see e.g., Fig. 3) through a WLS method implemented in the R-package rtop (Skøien et al., 2009; Skøien, 2009; http://intamap.geo.uu.nl/ jon/rtop/). Figure 3 illustrates the point variogram and regularised variograms of different catchment sizes, and a comparison between binned empirical and modelled semivariances.

Skøien and Blöschl (2007) focus on the specific, that is per unit area, runoff $q\left(x_{i}\right)$ at location $x_{i}$ along the stream network. Therefore we applied Top-kriging by referring to the specific low-flow index expressed in $1 \mathrm{~s}^{-1} \mathrm{~km}^{-2}, q_{355}\left(x_{i}\right)$.

\subsubsection{Results}

We assessed the reliability of the techniques and the uncertainty of the associated predictions of $Q_{355}$ in ungauged basins by applying a leave-one-out cross-validation procedure; this procedure often referred to as jack-knife in the literature and in the remainder of this study (see e.g., Efron, 1982; Zhang and Kroll, 2007; Brath et al., 2003; Castellarin et al., 2004, 2009). This method is extremely versatile and evaluates the performance of interpolation techniques by simulating the ungauged conditions for each and every one of the 51 basins in the study area. In the procedure we assume 

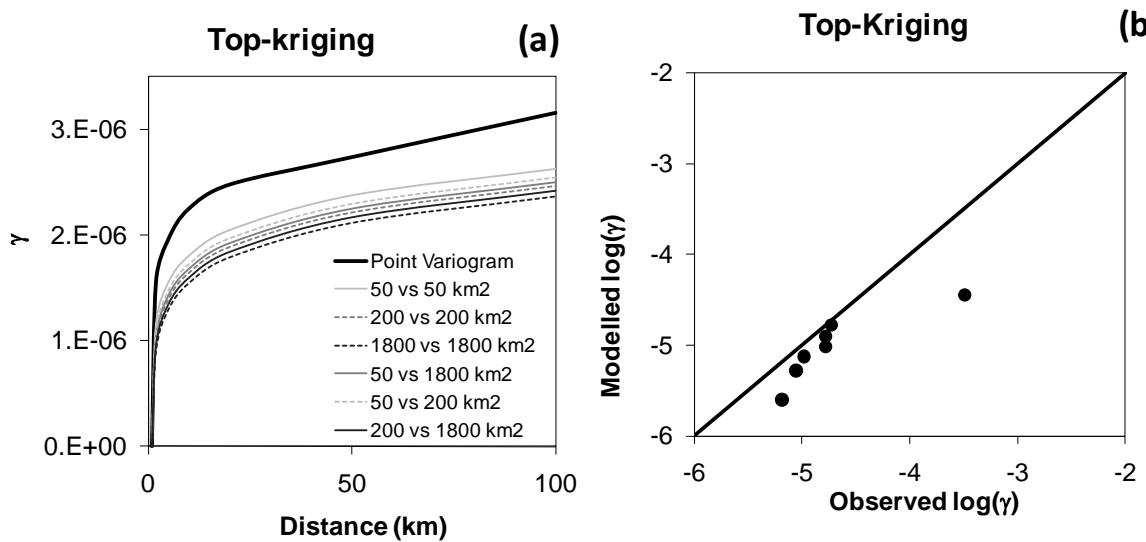

(b)

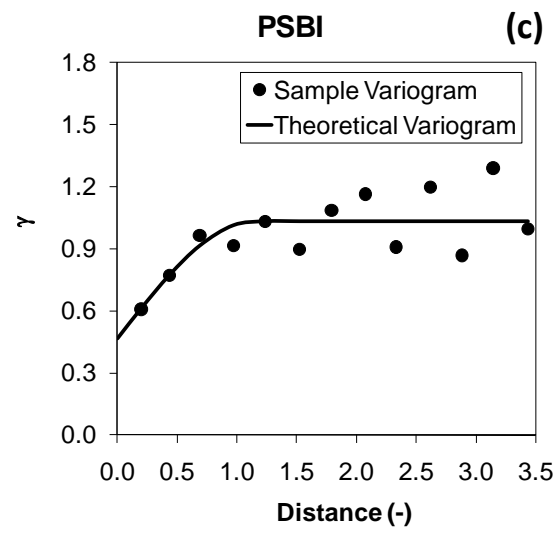

Fig. 3. Top-kriging: point variogram and regularised variograms of different catchment sizes (panel a); comparison between binned empirical and modelled semivariances, black line shows the perfect agreement (panel b). PSBI: experimental and theoretical (i.e., spherical) variograms for the study area (panel c).

Table 2. Regional-scale validation, performance indices obtained in cross-validation mode for the whole study area (for a subset of 48 catchments): $E$ is Nash-Sutcliffe efficiency, $\overline{\varepsilon_{\text {rel }}}$ is mean absolute relative error (PSBI is applied with and without information on the percentage of permeable area, $P$ ).

\begin{tabular}{lccc}
\hline Index & $\begin{array}{c}\text { PSBI } \\
\text { (Univ. Krig.) }\end{array}$ & $\begin{array}{c}\text { PSBI without P } \\
\text { (Univ. Krig.) }\end{array}$ & Top-kriging \\
\hline$E$ & $0.83(0.88)$ & $0.78(0.78)$ & $0.89(0.90)$ \\
$\overline{\varepsilon_{\text {rel }}}$ & $1.41(1.09)$ & $1.64(1.26)$ & $5.85(1.14)$ \\
\hline
\end{tabular}

one of the $N$ basins, let us say site $i$, to be ungauged, and predict the $Q_{355}$ value for this site on the basis of the remaining $N-1$ observations. Repeating this step $N$ times, considering in turn each of the basins as ungauged, we obtain $N$ crossvalidation estimates of $Q_{355}$ which can be compared with the corresponding observations. In particular, for the crossvalidation of PSBI we did not update the Principal Components (PC's) since the computation of PC's does not involve the $Q_{355}$ data at all and PC's are associated with catchment descriptors that can be derived also for ungauged sites (i.e. for site $i$ ). We updated the variogram $N$ times, instead, each time discarding the streamflow information for site $i$ and refitting the model to the available sample data. The scatterplots of empirical vs. estimated values of $Q_{355}$ resulting from the applications of PSBI and Top-kriging in cross-validation are shown in Fig. 4.

Jack-knife predictions and empirical values of $Q_{355}$ were quantitatively compared in terms of Nash-Sutcliffe efficiency criterion, $E$ (Nash and Sutcliffe, 1970) and mean absolute relative error, $\overline{\varepsilon_{\text {rel }}}$. In statistical modelling of flow indices, the term "coefficient of determination $R^{2}$ " is often used in- stead of $E$. We prefer to refer to $E$ to avoid possible ambiguities with the squared linear correlation coefficient, another commonly used performance index that, differently from $E$, cannot detect a bias in the predictions.

Table 2 reports the values of the performance indices computed on the basis of the 51 estimates of $Q_{355}$ and, within brackets, the same indices computed on the basis of a subset of 48 estimates. The subset results from the exclusion from the regional dataset of the three basins for which Topkriging gives large relative errors in cross-validation (red dots, Fig. 4). These gauges are all characterized by very low values of specific low flow, $q_{355}$. These catchments present $q_{355}$ values smaller than $0.15 \mathrm{ls}^{-1} \mathrm{~km}^{-2}$, whereas the average value of $q_{355}$ for entire study area is $5.131 \mathrm{~s}^{-1} \mathrm{~km}^{-2}$. For two of the three catchments the very small $q_{355}$ values derive from their atypical geomorphological characteristics: low permeability ( $P$ values are equal $\sim 0.1 \%$ and $8 \%$, and are among the smallest for the entire study region), closeness of the catchment boundaries to the shoreline and limited mean altitudes. The third catchment is a very small headwater catchment, characterized by high elevations and karst phenomena. Furthermore, these basins are geographically far apart from one another, and the neighbouring catchments are characterised by definitely higher $q_{355}$ values. All these circumstances limit the applicability of Top-kriging, whose estimates depend on catchments' boundaries only and result in significant overestimations of $q_{355}$ values (see Fig. 4), which results in remarkable relative errors due to the small $q_{355} \mathrm{em}$ pirical values. Therefore, we find it useful and fair to compare the performance of PSBI and Top-kriging indices with and without the three particular catchments.

Finally, it is well known that the information on catchment permeability might be hard to retrieve (see e.g., Brath et al., 2001). Nevertheless, such information may play a significant role on PSBI performance. To specifically address this 


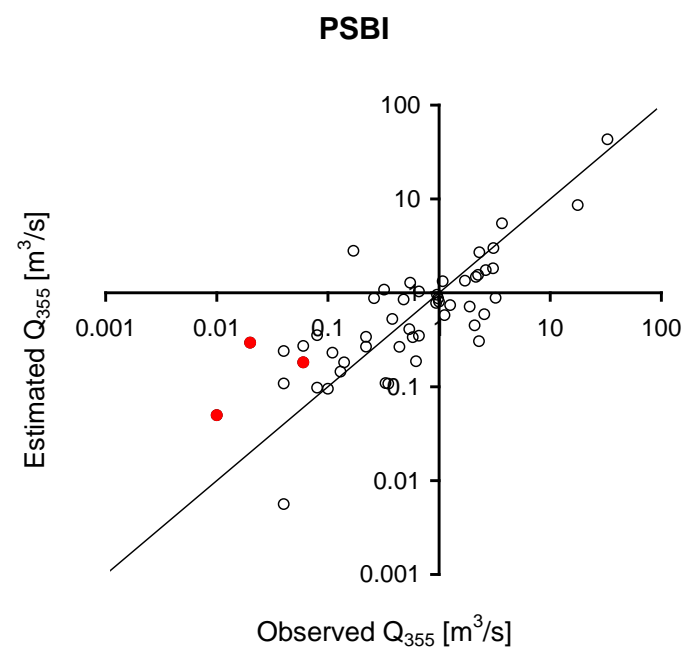

PSBI (without "P")

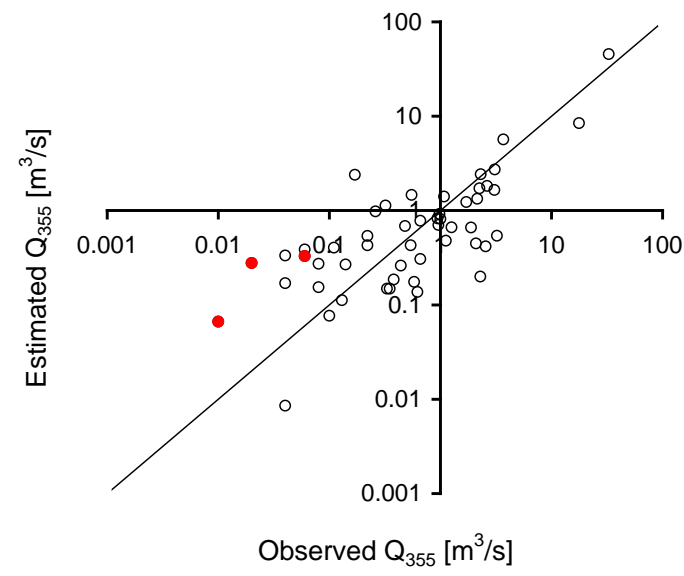

Top-kriging

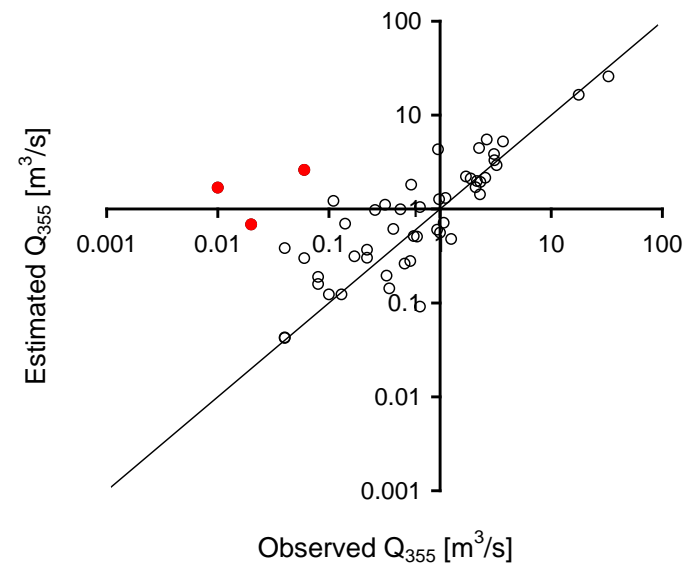

Fig. 4. Empirical values of $Q_{355}$ vs. estimated values obtained in cross-validation (PSBI is applied with and without information on the percentage of permeable area, $P$ ). point we further applied PSBI by dropping the information on percentage of permeable area (catchment descriptor $P$, see Table 1). Figure 4 and Table 2 illustrate the performance of cross-validated PSBI applied with or without $P$, and show that characterizing the permeability of basins reduces the uncertainty of $Q_{355}$ predictions. Nevertheless, this numerical experiment clearly shows that the performance loss is rather limited (see Table 2) and indicates, at least for the study region considered herein, that PBSI represents a valuable and reliable regionalization technique also when no information on catchment permeability is available.

The results indicate that, if we exclude the three peculiar basins, PSBI and Top-kriging have similar performances. This evidence is supported by the comparable values of the performance indices reported in Table 2. The performances of the two methodologies are similar in terms of $E$ with or without the three peculiar catchments, and, as results of the considerations stated above, get similar also in terms of relative errors when the three catchments are neglected.

\subsection{Catchment-scale Analysis}

To further advance the comparison, Top-kriging and PSBI were also implemented at the catchment scale to predict $Q_{355}$ in the Metauro basin (see Fig. 1). The Metauro catchment at Barco di Bellaguardia (site 1002 in Fig. 5) covers an area of $1043.6 \mathrm{~km}^{2}$ and counts 6 internal stream gauges (1 gauge per $\sim 150 \mathrm{~km}^{2}$, see Fig. 5). Empirical values of $q_{355}$ vary between $\sim 3$ and $\sim 0.31 \mathrm{~s}^{-1} \mathrm{~km}^{-2}$. For this application of PSBI and Top-kriging, only the streamflow data observed at the 7 stream gauges were considered (i.e., gauge 1002 together with 6 internal gauges).

A first analysis applied PSBI and Top-kriging to interpolate $Q_{355}$ along Metauro's stream network (see Sect. 4.2.1). A second analysis applied the two methodologies in crossvalidation and compared empirical and jack-knife predictions of $Q_{355}$ for the 7 considered stream gauges (see Sect. 4.2.2). Also in this case, only the hydrometric information observed at the 7 stream gauges illustrated in Fig. 5 was considered.

\subsubsection{Preparation of the dataset}

The catchment-scale application of both methodologies required the preliminary identification of the stream network, the delineation of a subdivision of the Metauro's into subcatchments on the basis of the confluences and network's layout (application of Top-kriging), and the evaluation of the nine considered geomorphologic and climatic descriptors (see Table 1) for all identified subcatchments (application of PSBI). To this end, we carried out a process characterized by four steps (see Fig. 6). This analysis allowed us to highlight the advantages and disadvantages of each methodology, emphasizing in particular the straightforwardness/complexity 

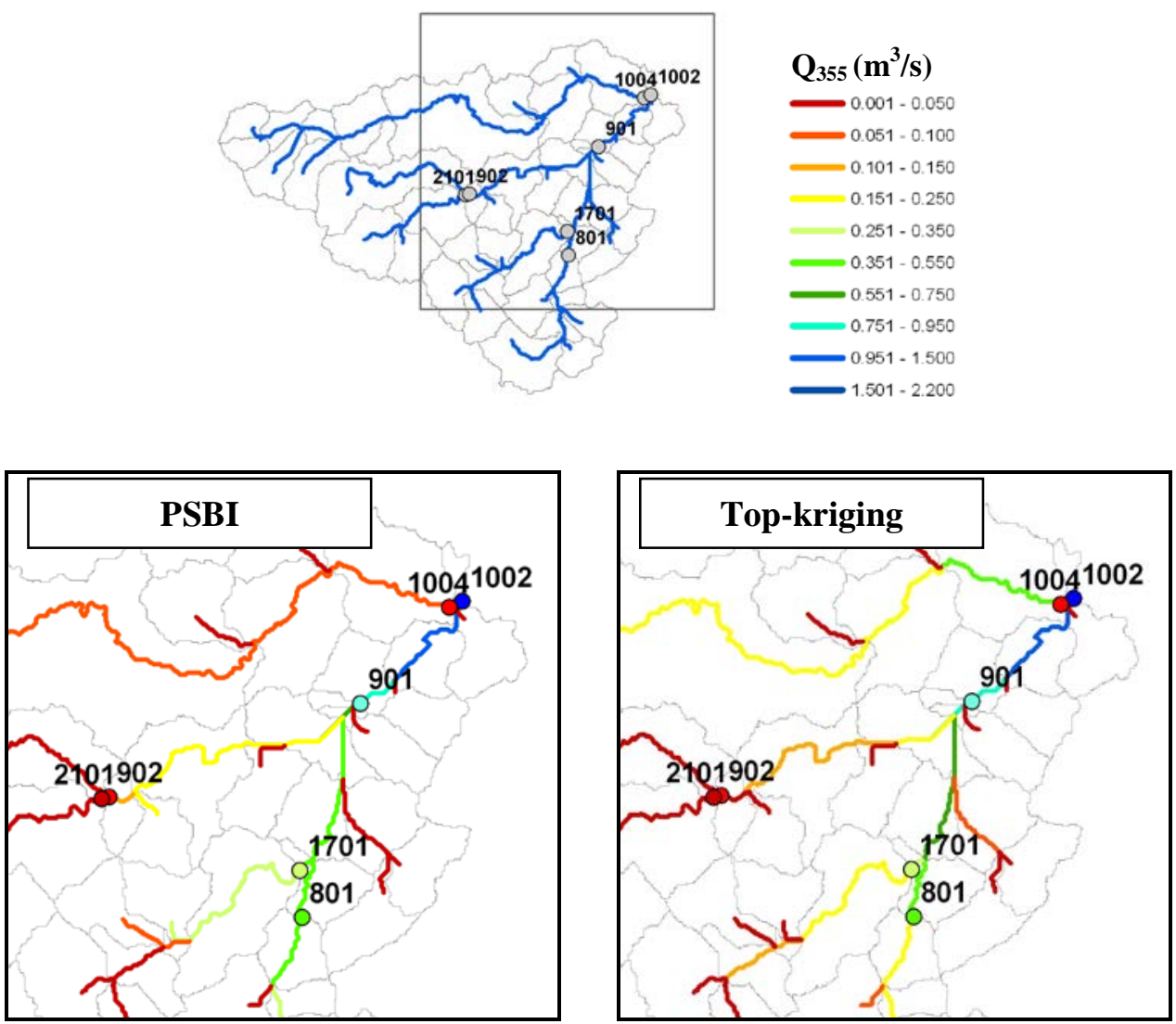

Fig. 5. Cross-validation estimates of $Q_{355}$ along the river network for PSBI (on the left) and Top-kriging (on the right): observed values are shown for available stream gauges as coloured dots; estimates are represented as coloured lines.

of all steps required for the preparation of the dataset required by the implementation of both techniques. This is a critical matter in the context of Prediction in Ungauged Basins (PUB).

Below we describe the four steps exemplified in Fig. 6, which we carried out in a GIS (Geographic Information System) environment:

1. Stream network and basin contours were identified from the 90m DEM (GIS processing 1 in Fig. 6). First we identified the stream network by means of the eightdirection-pour-point (or D8) algorithm (see e.g. Brath et al., 2002) on the basis of a suitable critical source area (CSA). CSA was identified by reaching an acceptable level of congruence between the river network retrieved from the DEM and that reported on 1:25.000 topographic maps. Afterwards, all subcatchments with drainage area $\geq 10 \mathrm{~km}^{2}$ were identified for the Metauro catchment, which resulted into 44 additional ungauged sub-basins (see Fig. 5).

2. A, $L, H_{\max }, H_{\text {mean }}, H_{\min }, \tau_{\mathrm{c}}$ and $\Delta \mathrm{H}$ were computed for each subcatchment from the $90 \mathrm{~m}$ DEM (GIS processing 2 in Fig. 6). The physiographical descriptors computed from the DEM were compared with the data reported in the literature (see Rep. No. 17; Min. LLPP., Italian Dept. of Public Works, various years) for the drainage areas of seven stream gauges belonging to the Metauro's catchment. All parameters retrieved from the DEM were found to be practically coincident with the literature values.

3. By combining catchment boundaries with a pedolithological map, the percentage of permeable area $(P)$ for each sub-basin was determined (GIS processing 3 in Fig. 6). Also in this case the congruence with the data reported in the literature was verified.

4. Mean Annual Precipitation, MAP, at catchment-scale was computed for all Metauro's sub-basins by using the precipitation data observed at several raingauges (see Fig. 6) and the Thiessen polygon technique (GIS processing 4 in Fig. 6).

Principal Components (PC's) are used when applying PSBI at catchment scale to fully characterise the physiographical space for the entire Metauro catchment. Therefore PC's of the catchment scale application were computed using the catchment descriptors derived as described above for 


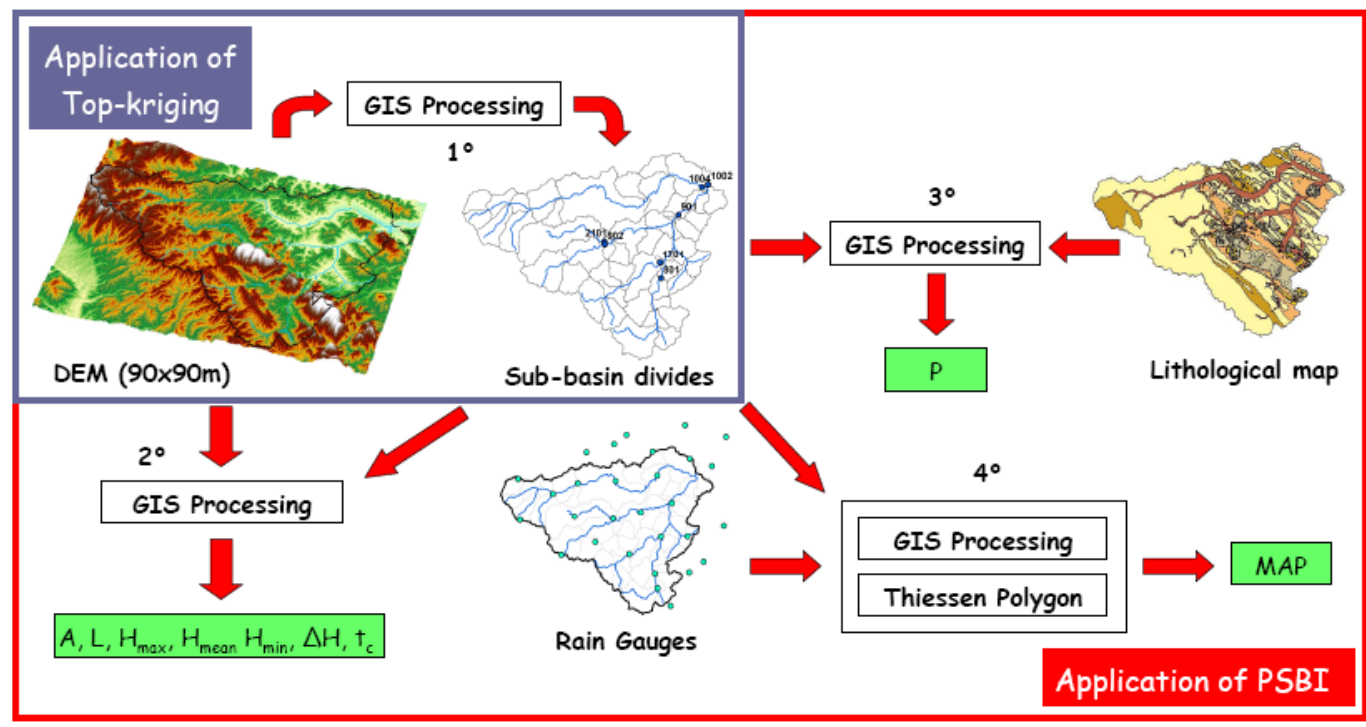

Fig. 6. Dataset preparation: outline of the process implemented for the identification of the dataset used for the application of the techniques and steps required for the application of Top-kriging (step 1) and PSBI (steps 1 to 4).

a total of 51 catchments, that is the Metauro catchment, the six internal gauged sub-basin and the 44 additional ungauged sub-basins identified at step 1 .

Figure 6 immediately points out that the preparation of the dataset for Top-kriging requires less steps than the preparation of the dataset for PSBI. Nevertheless, it is worth noting here that the part of the procedure that required a lot of "manual" input and that resulted to be the least straightforward was the identification of stream network and watershed boundaries (step 1). This results from the complex morphology of the study area and approximations associated with the adopted DEM. It is also worth remarking that this step is required for the application of both techniques: the application of Top-kriging requires the basin contours to be known in order to define size and nested structure of all catchments; the application of PSBI requires geomorphological and climatic descriptors computed or retrieved for each sub-basin.

As a commentary for the application in the PUB context of both methodologies, one should note that high-to-medium resolution DEM's for the entire world are accessible the on internet (see e.g. www.cgiar-csi.org). Also, referring in particular to the application of PSBI, it is worth remarking here that raingauge networks are generally quite dense in many regions of the world. For these reasons, the identification of all geomorphological and climatic parameters adopted in this study, except for $P$, can be easily performed in other geographical contexts. The percentage of permeable area, $P$, is a highly descriptive parameter for our study area (see e.g., Castellarin et al., 2004, 2009), yet complex to determine and to quantify, even though, as showed here, pedo-lithological maps can be used to this end.

\subsubsection{Results}

We applied Top-kriging and PSBI for predicting $Q_{355}$ along Metauro's river network. A previous application of Topkriging showed that this technique provides plausible and accurate predictions of streamflow-related variables along the stream network (e.g., specific 100-year flood, see Skøien et al., 2006, and specific low flows q(95), see Laaha et al., 2010). The possibility to perform the interpolation of the hydrometric index of interest along a stream network is still to be investigated for PSBI.

In Figure 5 we show the cross-validation predictions of $Q_{355}$ for PSBI (on the left) and Top-kriging (on the right). The estimated values are shown on stream network and the empirical values are shown at the 7 stream gauges where observed series of discharge are available.

We summarize in Table 3 the absolute relative error obtained at each stream gauge (cross-validation). The values reported in Table 3 indicate a slightly higher degree of accuracy for PSBI for five out of seven stream gauges.

In particular, if we consider the mountainous basins (higher mean elevations), slightly better results are found for PSBI at gauges 2101, 902, 801 and 1701 (in this order Biscuvio at Piobbico, Candigliano at Piobbico, Burano at Foci and Bosso at Cagli). When we move downstream the performance comparison indicates less clear results. Top-kriging cross-validation estimates are extremely close to $Q_{355}$ empirical values at sites 901 and 1002 (Candigliano at Acqualagna and Metauro at Barco di Bellaguardia, respectively), while Table 3 clearly indicates that PSBI outperforms Top-kriging at stream gauge 1004 (Metauro river at Calmazzo). The poor result for Top-kriging obtained at stream gauge 1004 
may result from the strong influence of stream gauge 1002 (Metauro at Barco di Bellaguardia). Both gauges are situated at a river junction and the low flow regime at the confluent river at gauge 1004 vastly differs from the regime of the main river at 1002. This situation contradicts the assumption of intrinsic stationarity of Top-kriging, i.e. similar low flows at close-by sites. As shown in previous studies, Top-kriging predicts even well in such a situation, if the heterogeneity is represented by the upstream gauge (Laaha et al., 2010), but performs rather poorly if no information about the heterogeneity is available. This situation is simulated by the cross-validation approach.

It is interesting to observe that the catchment scale application of PSBI and Top-kriging resulted in balancing performances. The average value of the minima of the relative errors in absolute value computed for the two methodologies is as low as $18 \%$ in cross-validation, which is definitely smaller than the mean values for the two methodologies (see Table 3). This is an important result that underlines how different the methodologies are, notwithstanding the common background philosophy (application of spatial interpolation techniques to regionalization of streamflow regime), and how low-flow predictions in ungauged sites could in principle benefit from a simultaneous application of both methodologies. An agreement between the predictions resulting from the application of the two methodologies supports a good reliability of the predictions themselves, whereas a discordancy for a particular portion of the study area should suggest to further investigate that area, perhaps by planning ad-hoc streamflow measurement campaigns.

\section{Discussion and conclusions}

This study aims at comparing two innovative regionalization approaches, namely Physiographical Space-Based Interpolation, or PSBI, and Top-kriging, for the prediction of lowflows indices in ungauged basins. Both methodologies rely heavily on the use of spatial interpolators for the regionalization of the streamflow information, even though they adopt two markedly different approaches. A quantitative comparison of the two methodologies has not been reported in the literature yet.

We focused on kriging-based approaches only (i.e., PSBI and Top-kriging) because a previous analysis performed for the same study area showed that PSBI enables one to deal with heterogeneous regions more effectively than traditional multiregression models, providing more accurate predictions of low-flow indices in ungauged basins (Castiglioni et al., 2009).

The results of our study point out that, if we exclude a very small number of catchments characterized by a peculiar lowflow frequency regime, the performances of Top-kriging and PSBI are very similar, this implies that both methodologies
Table 3. Catchment-scale cross-validation, relative errors in absolute value obtained for seven internal stream gauges of the Metauro's basin.

\begin{tabular}{rccc}
\hline Site Code & PSBI & Top-kriging & $\begin{array}{c}\text { Minimum } \\
\text { Value }\end{array}$ \\
\hline 801 & 0.12 & 0.54 & 0.12 \\
901 & 0.23 & 0.02 & 0.02 \\
902 & 0.34 & 0.39 & 0.34 \\
1002 & 1.20 & 0.01 & 0.01 \\
1004 & 0.40 & 3.04 & 0.40 \\
1701 & 0.10 & 0.52 & 0.10 \\
2101 & 0.30 & 0.91 & 0.30 \\
Mean Value & 0.38 & 0.77 & 0.18 \\
\hline
\end{tabular}

represent an effective alternative to traditional regionalization approaches (i.e. multiregression models).

Concerning the catchment scale, the Metauro application of PSBI and Top-kriging demonstrated that the latter technique is easier to implement, because the dataset preparation requires a fewer steps. The comparison between jack-knife predictions and empirical values of $Q_{355}$ for the 7 gauges located in the Metauro catchment point out that PSBI slightly outperforms Top-kriging, even though the performances are comparable.

Although the results are necessarily associated with the study region considered in the analysis, they provide useful and, to some extent, general indications that may aid the practitioner in the selection of the better methodology for the problem at hand. On the basis of the results obtained in cross-validation at regional and catchment scales one can identify the cases in which Top-kriging is expected to outperform PSBI and vice versa. We report some considerations on this point below.

A closer look at Table 3 shows that the performances of the two methods depend on the topological situation at the river network. Overall, Top-kriging outperforms PSBI at larger river branches (gauges 901, 902, 1002) while PSBI outperforms Top-kriging for headwater catchments, i.e. catchments without an upstream gauge (gauges 801, 1004, 1701, 2101). This is consistent with the finding of Laaha et al. (2010) who compared Top-kriging with regional regression for 325 Austrian catchments and found a similar behaviour. For Top-kriging, headwater catchments correspond to a boundary area in stream network topology where Top-kriging typically extrapolates the values of a downstream gauge to the upstream area. This yields larger prediction errors if the low flow regime changes in the extrapolated area, like it is frequently the case for the smaller headwater catchments in mountainous regions (an extreme example is gauge 1004 at Calmazzo). In this case, PSBI yielded better predictions, as it infers information from gauged information of similar catchments. PBSI, however, performs poorer at larger rivers. 
PBSI, like any multivariate technique, assumes a clear relationship between the low flow index and catchment processes represented by catchment characteristics. The aggregation of discharges at larger rivers leads to a mixing of different regimes and low-flow generating processes and therefore reduces the performance of multivariate techniques (Laaha and Blöschl, 2007; Laaha et al., 2010). In this case, Topkriging proved more suitable, as it does not rely on such relationships. The fact that the Metauro basin is dominated by headwater catchments gives rise to a somewhat better performance of PBSI than Top-kriging in this region.Both Top-kriging and PSBI perform smooth regional estimation by means of spatial interpolation. The main difference is that Top-kriging interpolates low flows in the geographic space (for this reason it may be listed among the geostatistical techniques, Pebesma, 2010), using information from the closest gauges at the river network, while PSBI interpolates low flows in a space of physiographical catchment characteristics, using information from the most similar gauges in terms of catchment characteristics. Top-kriging is solely based on spatial information and, therefore, requires that spatial heterogeneity of low flows is covered by the location of data points. Heterogeneity not covered by local data will yield higher predictive uncertainty. This is a major difference to multivariate techniques or PSBI, which can transpose such information without relying on local data. Multivariate techniques, however, require that spatial heterogeneity of low flows can be explained by the available catchment characteristics and the model. The fact that relevant catchment characteristics, such as storage coefficients or permeability, are to a large extent unknown, impedes the effectiveness of multivariate statistical techniques.

From these findings, we can conclude a complementariness of the two estimation methods. The methods are complementary in terms of the basic principle of spatial interpolation, because Top-kriging is based on proximity in geographic space while PSBI is based on proximity in terms of catchment characteristics. The methods are also complementary in terms of data requirements, since Top-kriging requires that heterogeneity of low flows is covered by the gauging network, while PSBI requires that heterogeneity to be covered by catchment characteristics and the model. Finally, the methods are complementary in terms of predictive performances, since Top-kriging yielded better results for homogeneous situations along the main rivers while PSBI yields better results for heterogeneous situation in headwater catchments. Furthermore, it is worth remarking here that the uncertainty associated with PSBI predictions evidently increases dramatically as we move outside the portion of physiographic space containing the empirical values. Top-kriging, instead, should provide a more accurate means to perform downstream extrapolations (i.e. predictions for catchments that are larger than all gauged catchment considered in the study area), provided that a network connectivity with upstream gauged catchments exists and physiographi- cal parameters do not change radically as we go downstream (hydrological homogeneity of the study region). Nevertheless, for both techniques a general comment holds. Like all kriging based methods (without drifts) extrapolation will make Top-kriging and PSBI converge to the expectation.

These different properties of the methods are important, especially for practical applications when predicting low flows of ungauged basins, where the choice of the method shall optimally be guided by available data and the hydrological situation. The complementariness of the methods also suggests a combination of the methods, to make best use of the merits of both techniques. In particular, the two methodologies could be integrated in two different ways. One could apply PSBI to Top-kriging residuals. Basins with similar morphoclimatic characteristics (e.g., headwater catchments) are expected to be close in the physiographical space and, considering the application of Top-kriging, characterised by similar prediction errors (i.e., sign and magnitude). The interpolation of these prediction errors on the physiographical space would enable the computation of a correction factor along the entire river-network. Alternatively, one may use Top-kriging to interpolate residuals from PSBI along the river-network, therefore correcting predictions based solely on geomorphoclimatic similarity on the basis of stream network connectivity. Even though these analyses are clearly out of the scope of the present study, we believe that this strategy would combine the advantages of the two methodologies and its implementation is the subject of future researches.

This study represents a preliminary effort, further analyses in different geographical and climatic contexts are needed for a more comprehensive assessment of these methodologies, their effectiveness for predicting low-flow in ungauged basins, and their degree of complementariness. As a final remark, the main focus of our analysis was to compare the methodologies in the context of predictions in ungauged basins (PUB), and therefore on the accuracy of the estimates at ungauged sites. Equally important are the estimates of the uncertainty of the low-flows provided by both methods which should be compared in future analyses.

Acknowledgements. The study has been partially supported by the Italian Government through its national grants to the programmes on "Advanced techniques for estimating the magnitude and forecasting extreme hydrological events, with uncertainty analysis" and "Relations between hydrological processes, climate, and physical attributes of the landscape at the regional and basin scales". We gratefully acknowledge the Civil Protection Agency of Marche Administrative Region for providing hydrological data and the CGIAR-CSI GeoPortal for providing SRTM 90m Digital Elevation Data (CIAT-CSI SRTM website: http://srtm.csi.cgiar.org). The useful comments and suggestions of Stacey A. Archfield, Ezder Pebesma and one anonymous reviewer are thankfully acknowledged.

Edited by: G. Di Baldassarre 


\section{References}

Bárdossy, A.: Calibration of hydrological model parameters for ungauged catchments, Hydrol. Earth Syst. Sci., 11, 703-710, doi:10.5194/hess-11-703-2007, 2007.

Basilevsky, A.: Statistical Factor Analysis and Related Methods: Theory and Applications, John Wiley, Hoboken, N. J., 1994.

Brath, A., Castellarin, A., Franchini, M., and Galeati, G.: Estimating the index flood using indirect methods, Hydrol. Sci. J., 46(3), 399-418, 2001.

Brath, Armando, Castellarin, Attilio, and Montanari, Alberto: Assessing the effects of land-use changes on annual average gross erosion, Hydrol. Earth Syst. Sci., 6, 255-265, doi:10.5194/hess6-255-2002, 2002.

Brath, A., Castellarin, A., and Montanari, A.: Assessing the reliability of regional depth-duration-frequency equations for gaged and ungaged sites. Water Resour. Res., 39(12), 1367, doi:10.1029/2003WR002399, 2003.

Burn, D. H.: Evaluation of regional flood frequency analysis with a region of influence approach, Water Resour. Res., 26(10), 22572265, 1990.

Castellarin, A., Burn, D. H., and Brath, A.: Assessing the effectiveness of hydrological similarity measures for flood frequency analysis, J. Hydrol., 241, 270-285, 2001.

Castellarin, A., Galeati, G., Brandimarte, L., Montanari, A., and Brath, A.: Regional flow-duration curves: reliability for ungauged basins, Adv. Water Res., 27(10), 953-965, 2004.

Castiglioni, S., Castellarin, A., and Montanari, A.: Prediction of low-flow indices in ungauged basin through physiographical space-based interpolation, J. Hydrol., 378, 272-280, 2009.

Castiglioni, S., Lombardi, L., Toth, E., Castellarin, A., and Montanari, A.: Calibration of rainfall-runoff models in ungauged basins: a regional maximum likelihood approach, Adv. Water Resour., 33(10), 1235-1242 doi:10.1016/j.advwatres.2010.04.009, 2010.

Cattell, R. B.: The Scree test for the number of factors, Multivar. Behav. Res., 1, 141-161, 1966.

Centamore, E., Pambianchi, G., Deiana, G., Calamita, F., Cello, G., Dramis, F., Gentili, B., and Nanni, T.: Carta Geologica, Geomorfologica, Idrogeologica, Scala 1:100.000. L'ambiente fisico delle Marche, Geologia, Geomorfologia, Idrogeologia, Ancona, 1981 (in Italian).

Chokmani, K. and Ouarda, T. B. M. J.: Physiographical space-based kriging for regional flood frequency estimation at ungauged sites, Water Resour. Res., 40, W12514, doi:10.1029/2003WR002983, 2004.

Cressie, N.: Statistics for spatial data. Wiley, New York, 1993.

Croker, K. M., Young, M. D. Z., and Rees, H. G.: Flow duration curve estimation in ephemeral catchments in Portugal, Hydrol. Sci. J., 48(3), 427-439, 2003

De Marsily, G., Lavedan, G., Bocuher, M., and Fasanino, G.: Interpretation of interference tests in a well filed using geostatistical techniques to fit the permeability distribution in a reservoir model, in Geostatistics for Natural Resources Characterization, edited by: Verly, G., David, M., Journel, A. G., and Marechal, A., 831-849, D. Reidel, Norwell, Mass, 1984.

De Marsily, G.: Quantitative hydrogeology, Academic Press, London, 1986.

De Marsily, G. and Ahmed, S.: Application of kriging techniques in groundwater hydrology, J. Geol. Soc. of India, 29, 57-82, 1987.
Efron, B.: The Jackknife, the Bootstrap and Other Resampling Plans, Society for Industrial and Applied Mathematics, Philadelphia, Pennsylvania, 1982.

Furey, P. R. and Gupta, V. A.: Space-time variability of low streamflows in river networks, Water Resour. Res., 36(9), 2679-2690, 2000.

Giandotti, M.: Previsione delle piene e e delle magre dei corsi d'acqua, Min. LL.PP., Servizio Idrografico Italiano, Memorie e studi idrografici, 8, (Rep. No. 2), Roma, 1934(in Italian).

Gustard, A., Bullock, A., and Dixon, J. M.: Low flow estimation in the UK, Institute of Hydrology, Report No. 108, 88 pp., append, 1992.

Hundecha Y., Ouarda, T. B. M. J., and Bárdossy, A.: Regional estimation of parameters of a rainfall-runoff model at ungauged watersheds using the "spatial" structures of the parameters within a canonical physiographic-climatic space, Water Resour. Res. 44, W01427, doi:10.1029/2006WR005439, 2008.

Isaaks, E. H. and Srivastava, R. M.: Applied Geostatistics, Oxford Univ. Press, New York, 1989.

Jackson J. E.: A User's Guide to Principal Components. Wiley, New York, 1991.

Journel, A. and Huijbregts, Ch.: Mining Geostatistics, Academic Press, 1978.

Laaha, G. and Blöschl, G.: A comparison of low flow regionalisation methods-catchment grouping, J. Hydrol., 323, 193-214, 2006a.

Laaha, G. and Blöschl, G.: Seasonality indices for regionalizing low flows, Hydrol. Process., 20, 3851-3878, 2006 b.

Laaha, G. and Blöschl, G.: A national low flow estimation procedure for Austria, Hydrol. Scie. J., 52(4), 625-644, 2007.

Laaha, G., Skøien, J., and Blöschl, G.: Spatial prediction on a river network: Comparison of Top-kriging with regional regression, Environmetrics, under review, 2010.

Ludwig, A. H. and Tasker, G. D.: Regionalization of Low-Flow Characteristics of Arkansas Streams, USGS Water-Resources Investigations Report 93-4013, 19 pp., 1993.

McDonnell, J. J. and Woods R.: On the need for catchment classification, J. Hydrol., 299, 2-3, 2004.

Nash, J. and Sutcliffe, J.: River flow forecasting through conceptual models, Part 1: a discussion of principles, J. Hydrol., 10, 282290, 1970.

Pebesma, E. J.: Multivariable geostatistics in S: the gstat package. Computers \& Geosciences, 30, 683-691, 2004.

Pebesma, E.: Interactive Comment, Hydrol. Earth Syst. Sci. Discuss., 7, C3351-C3354, http://www. hydrol-earth-syst-sci-discuss.net/7/C3351/2010/, 2010.

Penche, C.: Guida all'idroelettrico minore - Per un corretto approccio alla realizzazione di un piccolo impianto, Ed. European small hydropower association (ESHA), Bruxelles, 1998.

Reed, D. W., Jakob, D., Robinson, A. J., Faulkner, D. A., and Stewart, E. J.: Regional frequency analysis: a new vocabulary. Hydrological Extremes: Understanding, Predicting, Mitigating. Proceedings of the IUGG 99 Symposium, Birmingham., IAHS Publ. no. 255, 237-243, 1999.

Rossi, R. E., Mulla, D. J., Journel, A. G., and Franz, E. H.: Geostatistical tools for modelling and interpreting ecological spatial dependence, Ecol. Monogr., 62, 277-314, 1992.

Skøien, J. O.: Rtop - an R package for interpolation along the stream network, Geophysical Research Abstracts, Vol. 11, 
EGU2009-10533, 2009.

Skøien, J. O. and Blöschl G.: Spatiotemporal topological kriging of runoff time series, Water Resour. Res., 43, W09419, doi:10.1029/2006WR005760, 2007.

Skøien, J. O., Merz, R., and Blöschl, G.: Top-kriging - geostatistics on stream networks, Hydrol. Earth Syst. Sci., 10, 277-287, doi:10.5194/hess-10-277-2006, 2006.

Skøien, J., Pebesma, E. J., and Blöschl, G.: Rtop - an R package for interpolation along the stream network. In: Proceedings StatGIS 2009, Geoinformatics for Environmental Surveillance, edited by: Dubois, G., 2009.

Sivapalan, M.: Prediction in ungauged basins: a grand challenge for theoretical hydrology-invited commentary., Hydrol. Process., 17, 3163-3170, 2003.

Smakhtin, V. U.: Low flow in hydrology: a review., J. Hydrol., 240, 147-186, 2001

Telis, P. A.: Techniques for estimating 7-day 10-year low-flow characteristics for ungauged sites on streams in Mississippi. USGS Water-Resources Investigations Report 91-4130, 143 pp., 1992.
Vezzani, L. and Ghisetti, F.: Carta Geologica dell'Abruzzo. Regione Abruzzo - Settore Urbanistica - Beni Ambientali e Cultura, Pescara, 1998 (in Italian).

Vogel, R. M. and Fennessey, N. M.: Flow-duration curves. I: new interpretation and confidence intervals., J. Water Resour. Plann. Manage., ASCE 1994, 120(4), 485-504.

Vogel, R. M. and Kroll, C. N.: Regional geohydrologic-geomorphic relationships for the estimation of low-flow statistics, Water Resour. Res., 28(9), 2451-2458, 1992.

Wagener, T., Sivapalan, M., Troch, P., and Woods, R.: Catchment Classification and Hydrologic Similarity. Geography Compass, 1, 901-931. doi:10.1111/j.1749-8198.2007.00039.x, 2007.

Yadav, M., Wagener, T., and Gupta, H.: Regionalization of constraints on expected watershed response behavior for improved predictions in ungauged basins, Advances in Water Resources, 30(8), 1756-1774, doi:10.1016/j.advwatres.2007.01.005, 2007.

Zhang, Z. and Kroll, C. N.: The baseflow correlation method with multiple gauged sites, J. Hydrol., 347(3-4), 371-380, doi:10.1016/j.jhydrol.2007.09.025, 2007. 